\title{
O Modelo EEA: Definições, Unidade de Análise e Possíveis Aplicações
}

\section{The EEA Model: Definitions, Unit of Analysis and Possible Applications}

\author{
Maria C. D. P. Lyra* \\ Universidade Federal de Pernambuco, Recife, Brasil
}

\begin{abstract}
Resumo
Apresentamos as características empíricas do modelo EEA para o estudo do desenvolvimento do processo de comunicação mãe-bebê e da emergência do self. Introduzimos as definições, a unidade de análise e sugerimos algumas aplicações. Este modelo integra uma seqüência de três padrões de organização, denominados estabelecimento, extensão e abreviação (EEA). Expomos os conceitos básicos para a compreensão deste modelo (processo, tempo irreversível, historicidade, sistema de relações, indivíduo e "realidade virtual”) e as perspectivas teórico-metodológicas que o fundamentam, Sistemas Dinâmicos e Dialogismo, sobretudo na perspectiva de Bakhtin.

Palavras-chave: Processo de desenvolvimento; comunicação mãe-bebê; sistemas dinâmicos; dialogismo; self.

Abstract

We present the empirical characteristics of the EEA model, applied to study the development of the motherinfant communication process and the emergence of the self. We introduce the definitions, unit of analysis, and suggested applications. This model integrates three developmental patterns of organization of the mother-infant communication system: establishment, extension and abbreviation (EEA). We present the basic concepts (process, irreversible time, historicity, system of relationships, individual, and "virtual reality") and the two theoretical-methodological perspectives giving support to the model, Dynamic Systems and Dialogism, principally from Bakhtin's approach.

Keywords: Developmental process; mother-infant; dynamic Systems; dialogism; self.
\end{abstract}

O modelo EEA, aplicado ao estudo da emergência e desenvolvimento da comunicação mãe-bebê e do self, está baseado em duas perspectivas teórico-metodológicas, Sistemas Dinâmicos e Dialogismo, sobretudo na perspectiva de Bakhtin (para uso do termo "dialogismo", ver Holquist, 1990). Fundamenta-se, desta forma, na concepção do desenvolvimento humano como um processo histórico, relacional, interdependente e criativo que vai fazer emergir um sujeito psicológico único, diferenciado, mas também relacional e capaz de assumir o seu papel como autor da sua identidade (Lyra, 2006, no prelo).

Este artigo tem o objetivo de apresentar as características empíricas do modelo EEA, ou seja, as definições dos padrões de organização do sistema de comunicação em estudo, denominados de estabelecimento, extensão e abreviação (EEA), a unidade de análise e, finalmente, sugerir possíveis aplicações. A emergência do selfé explorada, particularmente, em relação às características da abreviação como etapa do desenvolvimento do processo de comunicação mãe-bebê.

\footnotetext{
* Endereço para correspondência: Rua Muniz Tavares, 147/1001, Jaqueira, Recife, PE,52050-170.E-mail:marialyra2005@yahoo.com.br

Agradecimentos ao $\mathrm{CNPq}$ - projeto integrado de pesquisa/bolsa de produtividade processo $\mathrm{n}^{\circ}$ 523550/96-0 - e aos colegas, colaboradores e amigos, Maria Clara F. Batista, Sílvio R. A. Salinas, Vilma A. M. de Queiroz, Letícia Scorsi e Emmanuelle $\mathrm{C}$. Chaves que fizerem sugestões valiosas a partir da leitura de versões preliminares deste artigo.
}

\section{O Modelo EEA: Fundamentos Conceituais e Síntese das Perspectivas Teórico-Metodológicas}

\section{Processo, Tempo Irreversivel e Historicidade}

O modelo EEA está voltado para o estudo do processo de desenvolvimento se detendo, assim, à questão de como ocorre este desenvolvimento. Torna-se então imprescindível a inclusão do tempo como elemento integrante do fenômeno do desenvolvimento (Fogel, 1993; Valsiner, 2001). Como tal, este tempo assume um caráter de tempo irreversível (Valsiner, 2002). A inclusão de um tempo irreversível tem como conseqüência a compreensão de que cada elemento envolvido no processo de desenvolvimento tem que ser considerado como sendo modificado - ou podendo ser modificado - porque é passível de transformação durante o transcorrer deste processo (Lyra, 2006, no prelo). Trata-se, assim, de um tempo histórico que carrega a abertura de possibilidades e o fechamento de outras possibilidades no decorrer do processo de desenvolvimento (Lyra \& Winegar, 1997). Chamamos de historicidade este tempo histórico porque integra à concepção de gênese a projeção para o futuro de todo sistema psicológico. Esta projeção é ao mesmo tempo baseada no passado, mas inclui a dimensão do futuro ainda desconhecido. Isto quer dizer que, pelo menos em ciências humanas, temos que lidar com este aspecto inescapável que se impõe caracteristicamente quando olhamos para a natureza semiótica do funcionamento humano (Valsiner, 2001, 2002; Vygotsky, 1986). 


\section{Sistema de Relações, Indivíduo e "Realidade Virtual"}

O modelo EEA tem, também, como fundamento o conceito de sistema de relações. Este sistema é entendido como construindo a própria relação e os indivíduos, ambos emergindo de um mesmo processo de desenvolvimento. A necessidade de conceber, em conjunto, tanto relações como indivíduos não é estranha nem mesmo aos sistemas físicos. Trata-se de um requisito de natureza ontológica que está na base desta aparente dualidade: a idéia de relação requer a existência de indivíduos em trocas dinâmicas, mesmo se considerarmos a realidade física do movimento browniano de partículas individuais interagindo em um fluido (Império-Hamburger, Carvalho \& Pedrosa, 2003).

Propomos assim que a idéia de sujeito, indivíduo, eu ou self $^{1}$ é um requisito fundamental para a compreensão do ser humano. Propomos ainda que o sistema de comunicação seja o responsável pela construção de uma organização característica que possibilita a emergência de uma "realidade virtual' (Sinhá, 2004) que existe paralela à nossa capacidade sensorial, como uma ampliação e transformação desta, na qual emerge e se constitui o self. Esta "realidade virtual" representa os primórdios da nossa capacidade semiótica ou simbólica.

\section{Sistemas Dinâmicos}

A nossa utilização dos conceitos advindos da perspectiva dos Sistemas Dinâmicos na construção e conceituação do modelo EEA está baseada em dois argumentos fundamentais. $\mathrm{O}$ primeiro deles diz respeito à idéia de que o processo de desenvolvimento é um fenômeno em constante transformação, dando lugar tanto a períodos de estabilidade como de mudança. Este processo de transformação se dá em um sistema de relações historicamente construídas que ocorrem em um tempo irreversível. Portanto, trabalha-se com um processo de natureza essencialmente histórica. $\mathrm{O}$ segundo argumento refere-se ao mecanismo que possibilita tal desenvolvimento; trata-se da tendência de todo sistema vivo à auto-organização, (Lewis, 2000; Thelen \& Smith, 1994). A auto-organização é um mecanismo que resulta das trocas entre os elementos que compõem o sistema, possibilitando novos níveis de organização que constituem o desenvolvimento. A tarefa do investigador consiste no discernimento dos padrões de co-ação que definem as transformações e os níveis de organização de um dado sistema ao longo do tempo. Esta investigação conduz a compreensão tanto dos períodos de maior estabilidade do sistema como dos períodos de instabilidade, que caracterizam as fases de mudança. Ela se dá a partir da micro-análise das transformações que ocorrem no sistema em tempo real (micro-analítico) que são agrupadas como exibindo, caracteristicamente, períodos de estabilidade ou de mudança considerando o tempo do desenvolvimento (macro-analítico) (Thelen \& Ulrich, 1991). Desta forma, na perspectiva dos

\footnotetext{
${ }^{1}$ Os termos, sujeito, indivíduo, eu ou self são concebidos como equivalentes neste texto. No contexto das referências à Bakhtin, sujeito dialógico e self são utilizados indiscriminadamente.
}

Sistemas Dinâmicos, torna-se impossível (e sem sentido) a identificação de variáveis independentes e variáveis dependentes, uma vez que os elementos do sistema interagem e se modificam ao longo do tempo. Assim, a chave da compreensão de qualquer sistema está no discernimento do seu processo de auto-organização. Este conceito tanto inclui aspectos de ordem biológica como social, estando o sujeito inserido no ambiente específico onde ocorre o seu desenvolvimento.

Além do conceito de auto-organização dois outros conceitos advindos desta perspectiva, atratores e emergência do novo, merecem uma exposição. O conceito de atrator é um dos aspectos mais importantes para discernir o processo de estabilidade e mudança dos Sistemas Dinâmicos. Um atrator - ou estado atrator - pode ser entendido como uma região em que o sistema se estabiliza. Esta região pode ser vista de diferentes maneiras, dependendo do comportamento do sistema em estudo. Por exemplo, tendo como referência o sistema de comunicação, o atrator pode ser uma permanência em um padrão característico de troca comunicativa - trocas abreviadas (abreviação, definição abaixo); ou uma flutuação sistemática entre dois padrões característicos de trocas comunicativas - trocas abreviadas e trocas prolongadas (extensão, definição abaixo); ou ainda a repetição de um mesmo padrão se investigarmos diferentes dimensões dessas trocas, partindo das mais macroscópicas para aquelas mais microscópicas - trocas abreviadas, considerando tanto os turnos entre os parceiros como os elementos (ações) que compõem esses turnos que também se apresentam abreviados. O sistema apresenta, então, um comportamento de quase-estabilidade. Surgem, todavia, novos atratores ao longo do tempo. Quando isto ocorre, o sistema sofre um processo de transformação ou de mudança, permanecendo instável durante certo período, até que, novamente, se estabiliza em um novo padrão de organização. Nestes períodos de instabilidade, diferentes atratores atuam ao mesmo tempo. Cada atrator representa uma opção de caminho - ou trajetória - que vai caracterizar o desenvolvimento futuro deste sistema (Fogel \& Lyra, 1997; Lyra, 2000, 2006, no prelo; Pantoja \& Nelson-Goens, 2000; Thelen \& Smith, 1994). Considerando o modelo EEA, cada um dos padrões de organização do sistema de comunicação proposto, estabelecimento, extensão e abreviação, são períodos de quase-estabilidade, e podem ser considerados como atratores que atuam no sistema de comunicação aqui estudado: as trocas mãe-bebê. O mecanismo de passagem de um padrão de organização para um outro guarda características de indeterminação (Fogel, Lyra \& Valsiner, 1997). É justamente nessas passagens entre níveis de organização que emergem as novas formas ou novos padrões de organização. Existe, todavia, um jogo constante entre a determinação, proveniente da história de construção de um dado sistema, e a indeterminação, inerente ao momento de criação do novo (Lyra \& Winegar, 1997). Embora os sistemas físicos e mesmo os sistemas biológicos possibilitem o uso de modelos matemáticos (Haken, 1983), na Psicologia a utilização dos conceitos provenientes da perspectiva dos Sistemas Dinâmicos tem sido realizada, sobretudo, de forma 
analógica (Thelen \& Smith; van Geert, 1994); exceção a este fato, utilizando modelos matemáticos, está no trabalho de van Geert (1994) e Molenaar (Nesselroade \& Molenaar, 2003).

\section{Dialogismo}

A idéia de diálogo está filiada a uma corrente de pensamento em ciências humanas que tem como requisito a concepção de um sujeito psicológico (Hermans \& Kempen, 1993; Marková, 1987, 1990). Isto quer dizer que o desenvolvimento ocorre, ao mesmo tempo, em um sistema de relações que adquirem níveis de organização cada vez mais complexos (resultantes de um processo de auto-organização), mas que apresenta a característica de ser também construtor de indivíduos, sujeitos ou selves; é, portanto, um fenômeno essencialmente relacional e individual. O processo de diferenciação do sujeito humano exige, também, a criação de uma "realidade virtual” (Sinhá, 2004) que duplica e transforma o mundo dos sentidos. Esta realidade interiorizada é o que chamamos de capacidade simbólica ou semiótica. Explicando melhor, o sujeito psicológico humano é, ao mesmo tempo, um ser relacional e individual que emerge conjuntamente com uma nova dimensão da realidade, aqui chamada de "realidade virtual".

$\mathrm{O}$ trabalho do cientista que se propõe a investigar a emergência do sujeito humano necessita, primeiramente, caracterizar qual a natureza do sistema de relações que possibilita a emergência desse sujeito. Trata-se de um requisito advindo da própria perspectiva adotada pelos teóricos dos Sistemas Dinâmicos: conhecer e delimitar a natureza do sistema em estudo (Thelen \& Smith, 1994; van Geert, 1994). A nossa resposta para esta caracterização é de que este sistema diz respeito ao processo de desenvolvimento da comunicação social humana desde os primeiros momentos de vida do bebê (Lyra, 2000; Lyra \& Rossetti-Ferreira, 1995; Lyra \& Winegar, 1997). Assim, o modelo EEA se aplica ao estudo do desenvolvimento da comunicação humana fazendo uso tanto de conceitos advindos da perspectiva dos Sistemas Dinâmicos como daqueles que decorrem do Dialogismo proposto por Bakhtin.

Três aspectos, de natureza conceitual, caracterizam o sistema das relações sócio-culturais ou sociogenéticas que compõe a comunicação - ou a troca dialógica. Estes estão presentes desde o início o nascimento do bebê e, de alguma forma, desde o período pré-natal. São eles: a participação da história cultural através da história ontogenética nas trocas dialógicas, o caráter relacional, histórico, interdependente e criativo do diálogo, e a diferenciação do self a partir deste diálogo.

A participação da história cultural através da história ontogenética nas trocas dialógicas propõe que esta história é necessariamente integrada e reconstruída ao criar o sujeito psicológico humano, através do sistema de comunicação ou diálogo, evidente desde nascimento do bebê. O sistema de comunicação aqui focalizado, aquele que compreende as trocas mãe-bebê, vai guardar limites e possibilidades culturalmente construídos que são inerentes a diferentes ins- tâncias da história cultural. Alguns são mais gerais - por exemplo, aqueles característicos da linguagem - e alguns mais específicos - por exemplo, valores da nossa cultura ocidental; ainda outros, mais específicos, dizem respeito à história do grupo social, da família e da mãe/adulto que interage com o bebê (Lyra, 1998). Propomos, como caminho frutífero na análise sociogenética, a investigação cuidadosa das características do processo de auto-organização do sistema de comunicação - seus períodos de quase-estabilidade e mudança - visando discernir os mecanismos processuais que fazem emergir as primeiras manifestações de uma mediação anterior ao símbolo (no sentido de "duplicação" e transformação da realidade, como foi anteriormente referida).

Assumimos que desde o nascimento o bebê acha-se inserido em uma dinâmica relacional, histórica, interdependente e criativa (Bråten, 1988; Fogel, 1993). Isto é o diálogo (Lyra, 2000; Lyra \& Rossetti-Ferreira, 1995; Lyra \& Winegar, 1997). Cada troca comunicativa é entendida como pertencente a ambos os parceiros, impossibilitando a separação de um emissor, de um receptor e da própria mensagem. Adotamos dessa forma uma perspectiva processual, dinâmica, contínua e criativa do processo de comunicação, que se opõe a uma visão discreta da comunicação (Fogel, 1993).

Tanto a perspectiva dos Sistemas Dinâmicos, porque aceita a mútua transformação dos elementos que compõem o sistema em desenvolvimento, como a perspectiva Dialógica (Hermans \& Kempen, 1993; Marková, 1987), concebem a coexistência de contradições como inerentes aos sistemas em desenvolvimento. Desta forma, é possível conceber que as aquisições do desenvolvimento pertençam, ao mesmo tempo, a cada sujeito e à relação dialógica que, necessariamente, inclui o parceiro. Este caráter de interdependência de cada parceiro social na relação dialógica é o primeiro aspecto que define a natureza específica dos sistemas de relações sociais que caracterizam a comunicação, ou o diálogo, e seu desenvolvimento.

A nosso ver, as concepções advindas da perspectiva dos Sistemas Dinâmicos não nos permitem abarcar esta dualidade necessária expressa na existência de relações e indivíduos que emergem e se desenvolvem inseridos em um mesmo processo de desenvolvimento. Todavia, da perspectiva dos Sistemas Dinâmicos, destacamos a necessidade de investigar o processo de auto-organização do sistema em estudo. Por outro lado, as idéias elaboradas pelo Dialogismo, particularmente, o Dialogismo desenvolvido por Bahktin (1986, 1993), nos oferecem um instrumental que possibilita tratar o processo de emergência do sujeito psicológico ocorrendo no sistema de relações sociais desde o nascimento do bebê ou mesmo desde o início da vida. Visando elaborar o aspecto de diferenciação do self a partir do diálogo, vamos descrever a coexistência da relação e dos parceiros a partir das idéias de Bakhtin.

\section{O Sujeito Dialógico segundo Bakhtin}

Dois aspectos do Dialogismo proposto por Bakhtin $(1986,1993)$ são extremamente relevantes para o modelo 
EEA, no que se refere à emergência e constituição do self: a existência de um único lugar - no tempo e no espaço possível de ser ocupado pelo sujeito e a característica de "responsividade".

Nessa perspectiva, a idéia de indivíduo está baseada em um axioma que estabelece a existência de um único lugar no mundo onde existe um sujeito. Este lugar - espacial e temporal - só é ocupado por uma única pessoa no transcorrer da autobiografia da sua vida. Esta autobiografia é escrita por cada indivíduo como autor. O sujeito é autor de sua própria história, simplesmente porque não há outra possibilidade para que ele exista. Sem autoria não há diálogo possível no sentido genuíno da troca criativa que caracteriza o diálogo. Apenas desta perspectiva o diálogo é constitutivo da pessoa humana. Assim é que se distingue e se aplica o Dialogismo.

Bakhtin também propõe uma idéia complementar. Do lugar único que cada um ocupa, só existe uma possibilidade de existência, a inescapável necessidade de responder ao mundo que nos cerca. Bakhtin utiliza a expressão "não temos álibi possível”, porque responder ao mundo que nos cerca não é uma escolha, mas uma condição para existir (Bakhtin, Estetika, p.179, citado por Holquist, 1990, p. 29). Ainda, este mundo ao qual respondemos é um mundo de outros que nos responde também porque o diálogo é absolutamente pervasivo. Tornando mais claro, este mundo é o mundo social - um mundo de selves - característico da espécie humana.

Considerando o modelo EEA, estes dois aspectos do Dialogismo servem de base para a análise das características do período de quase-estabilidade, que define o padrão de organização do diálogo denominado abreviação. A abreviação identifica uma organização do diálogo mãebebê na qual se vislumbra um parceiro bebê começando a exibir um grau primeiro de diferenciação como sujeito, pois a qualidade dessas trocas sugere o início da criação de uma "realidade virtual" na qual os parceiros se inserem. Nesta realidade emergente o bebê ocupa um único lugar possível, evidente a partir da análise da história de construção do diálogo. Deste lugar, ele responde ao outro, mesmo que nada faça, e este outro, de forma inescapável, lhe responde também.

\section{O Modelo EEA: Definições e Unidade de Análise}

\section{As Definições}

O modelo EEA propõe que o processo de comunicação mãe-bebê seja construído obedecendo a uma seqüência de padrões organizacionais que se distinguem pelas diferentes características das trocas mãe-bebê. Estas trocas, sem a mediação do objeto (face-a-face, FF) ou com esta mediação (mãe-objeto-bebê, MOB), exibem níveis evolutivos (ou desenvolvimentistas) que possibilitam incluir os aspectos generalizáveis e as particularidades presentes em cada díade mãe-bebê estudada (Molenaar \& Valsiner, 2005). Ambos são inerentes à história de cada díade. Cada um desses padrões exibe um tipo característico de negociação entre os parceiros. Assim, este conjunto de três conceitos visa representar os processos subjacentes ao desenvolvimento da comunicação mãe-bebê, particularmente durante os primeiros oito meses de vida pós-natal do bebê. Estes processos se caracterizam por uma dinâmica entre os parceiros que exerce uma atividade de recorte, destaque, diferenciação ou "escolha”, que chamamos de dinâmica dialógica de recorte (Lyra, 1998), conceito que teve sua origem nas idéias de De Lemos $(1981,1985)$.

A dinâmica dialógica de recorte propõe que a interação entre parceiros ocorre através do destaque ou recorte de pelo menos uma ação (ou conjunto de ações) que se torna objeto de negociação. Além disto, e destacando o caráter relacional da atividade de recorte aplicado sobre o fluxo de ações dos parceiros, utilizamos uma analogia relativa à idéia de figura-fundo, originária dos estudos de percepção; a díade "escolhe" pelo menos uma dessas ações (ou conjunto de ações) para que se torne figura em relação ao fluxo constante e complexo de outras ações dos parceiros, que adquirem a função de um fundo. Os conceitos de estabelecimento, extensão e abreviação estão baseados nas características construtivas desta atividade de recorte. Eles constituem padrões de organização que foram historicamente construídos a partir das sucessivas atividades de recorte efetuadas pela díade mãe-bebê; possibilitam abarcar, a nível macroscópico, etapas do desenvolvimento do sistema de comunicação mãe-bebê na faixa etária focalizada.

Considerando esta atividade construtiva, podemos definir o estabelecimento, a extensão e a abreviação:

\section{Estabelecimento}

Através de sucessivas ou concomitantes ações dos parceiros, que "recortam" o fluxo de atividades da díade, pelo menos um elemento das trocas diádicas é construído de forma partilhada pela díade. Este elemento se torna "figura" em relação a um "fundo" de outras ações realizadas pela díade. Por exemplo, o olhar mútuo entre os parceiros, considerando as trocas face-a-face (Figura 1a), na próxima página, ou o olhar dos parceiros para o objeto, considerando as trocas que envolvem objetos (Figura 2a), na próxima página. São trocas de curta duração - inferior ou igual a seis turnos ${ }^{2}$.

\section{Extensão}

O elemento ou os elementos previamente estabelecidos tornam-se um "fundo" em relação ao qual a díade pode "recortar" e negociar, elaborando de modo mais prolongado, outros elementos como "figuras". Por exemplo, nas trocas face-a-face, tendo estabelecido o contato de olhar mútuo, podem ser negociados sorrisos, vocalizações, movimentos, etc, de forma elaborada e prolongada - superior a seis turnos (Figura 1b), na próxima página. Considerando o olhar conjunto dos parceiros para o objeto como fundo, os movimentos dos braços/mãos do bebê para o objeto podem ser negociados durante trocas prolongadas que focalizam estes movimentos (Figura 2b), na próxima página.

\footnotetext{
2 A conceituação do número de turnos - duração curta ou prolongada - pode sofrer ligeira variação dependendo da história particular de cada díade estudada.
} 


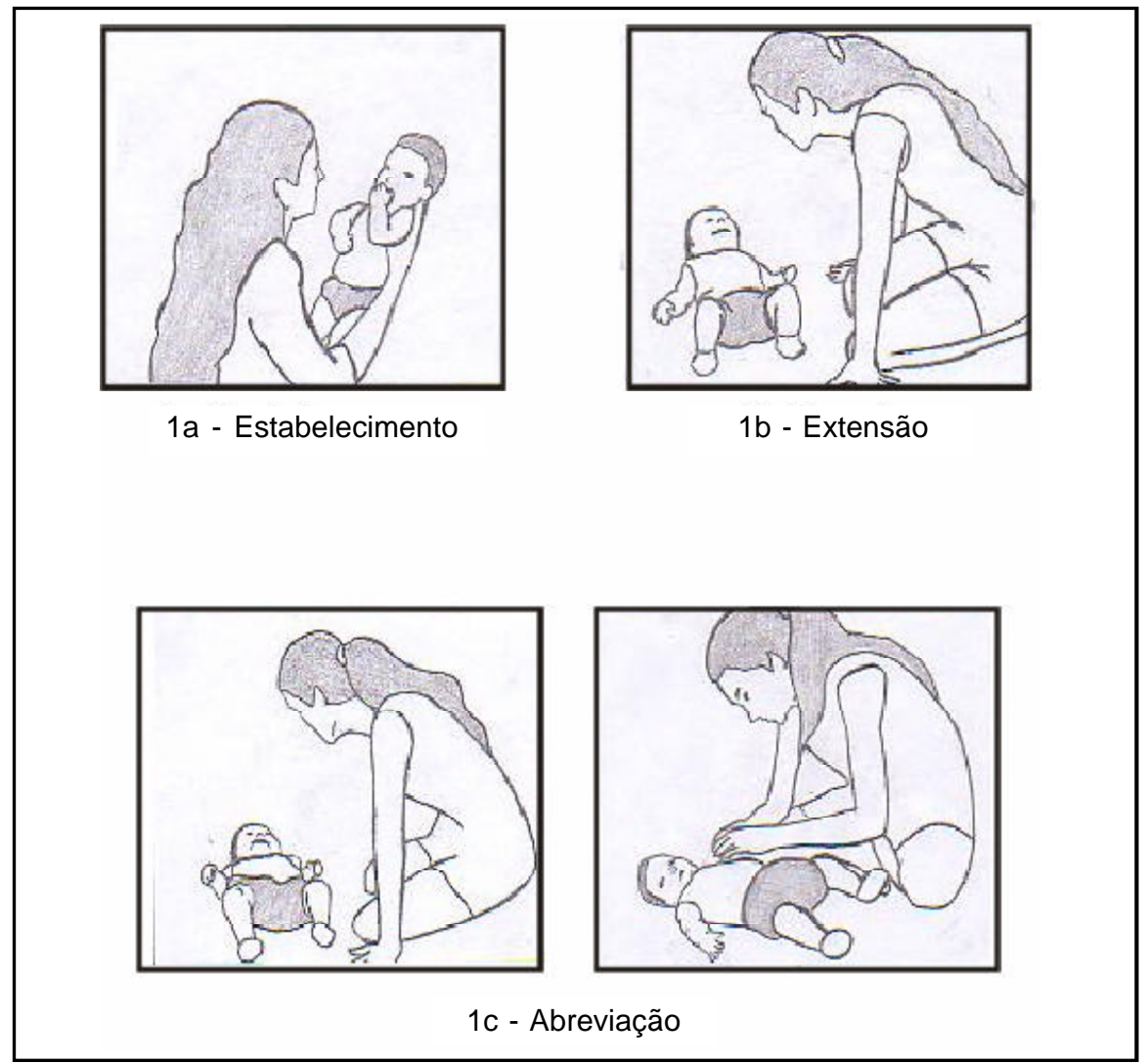

Figura 1. Ilustrações face-a-face.

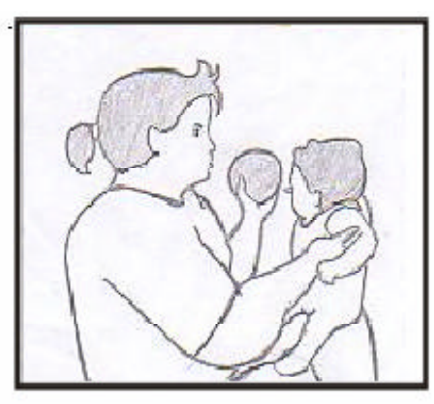

$2 a$ - Estabelecimento

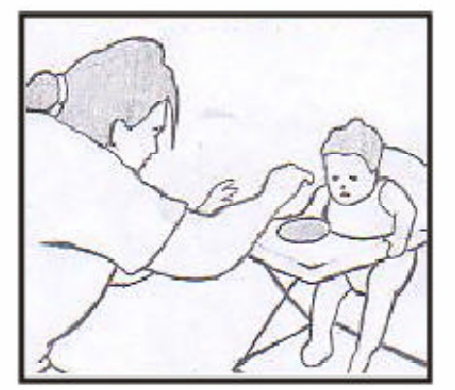

2c - Abreviação

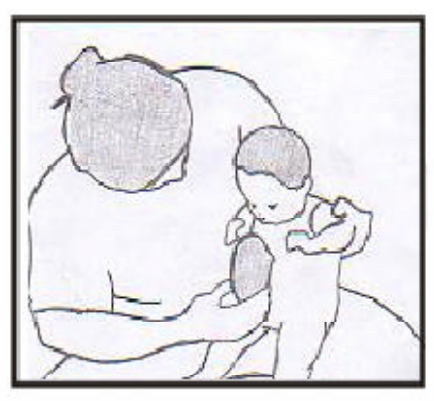

$2 b-$ Extenção

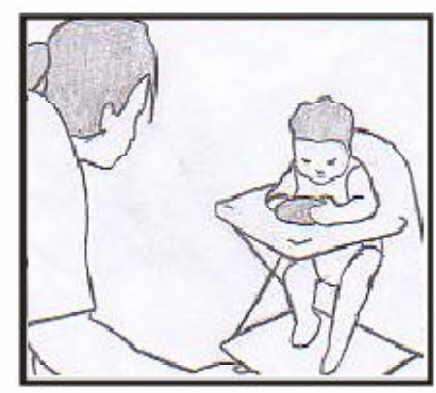

Figura 2. Ilustrações mãe-objeto-bebê. 


\section{Abreviação}

Trocas de curta duração - inferior ou igual a seis turnos - executadas pela díade através de um ajustamento mútuo rápido e fácil, em que os elementos anteriormente negociados e trabalhados pela díade, de forma prolongada, aparecem de modo reduzido ou condensado (abreviados). Por exemplo, considerando as trocas face-a-face, a díade utiliza um rápido contato de olhar acompanhado ou não de alguns elementos anteriormente negociados (sorriso, movimentos, por exemplo) (Figura 1c). Dando outro exemplo, tanto a mãe como o bebê, de forma ajustada, rápida e suave, dirigem o olhar para um objeto, que é então oferecido pela mãe e imediatamente segurado pelo bebê (Figura 2c). (Ver, mais adiante, a descrição mais detalhada da abreviação no que se refere à emergência do sujeito dialógico).

Considerando as características de "imediaticidade" no estabelecimento das trocas, suavidade no ajuste mútuo entre os parceiros e quantidade de turnos que compõem as trocas diádicas, podemos dizer que as características de cada período de quase-estabilidade são (Lyra \& Souza, 2003):

Estabelecimento. As trocas não são imediatamente estabelecidas nem suavemente ajustadas e se caracterizam por um pequeno número de turnos de curta duração entre os parceiros;

Extensão. As trocas passam a ser imediatamente estabelecidas, a suavidade dos ajustes mútuos vai crescendo no decorrer do período da extensão; as trocas são longas e o número de turnos é grande;

Abreviação. As trocas são imediatamente estabelecidas, suaves, de curta duração e contendo um número reduzido de turnos entre os parceiros.

É importante destacar três aspectos. O primeiro se refere ao significado do que é entendido como trocas face-aface $(\mathrm{FF})$; o segundo relaciona-se às características das trocas mediadas pelo objeto (MOB), ambas estudadas através do modelo EEA; e o terceiro refere-se a uma explicitação de como são investigadas e compreendidas as trocas abreviadas - abreviação - no sentido de possibilitarem a análise do processo de emergência do self.

As Trocas FF. Na nossa sociedade ocidental as trocas mãebebê que ocorrem face-a-face parecem ser muito freqüentes (Adamson, 1995; Schaffer, 1984). Apesar de reconhecer que em algumas sociedades indígenas este hábito é pouco usual, isto é, dialogar "olho-no-olho" com o bebê, assim como brincar com o bebê (por exemplo, os índios Maya, segundo Bornstein, \& Tamis-LeMonda, 2001), não se pode negar que, em algum momento, o bebê vai se achar em posição de amamentação. Essa situação possibilita necessariamente que os rostos da mãe e do bebê fiquem disponíveis um para o outro. Além disso, todo o cuidado físico que o recém-nascido necessita para sobreviver tem que ser feito, de alguma maneira, em uma posição que possibilita o contato face-a-face. Desta forma, este tipo de troca mãe-bebê necessariamente ocorre em algum momento inicial da vida do bebê.
Este primeiro tipo de diálogo mãe-bebê foi conceituado por Trevarthen (1998) como caracterizado por uma “intersubjetividade primária”. Trata-se de um diálogo basicamente afetivo-emocional, em que os parceiros conseguem, mutuamente, perceber e responder a estados emocionais, motivacionais e a emoções específicas que conduzem as trocas e constituem um elo de partilha entre eles. Não entendemos esses diálogos como uma fusão de emoções entre os parceiros, mas como um elo que já contém características intersujetivas (Bråten, 1988). Dessa forma, o essencial nas trocas FF é o desenrolar de um diálogo que não é mediado pelo mundo exterior aos parceiros, mas que tem um nítido cunho afetivo-emocional.

Essas trocas são perfeitamente passíveis de serem construídas sem que haja o contato do olhar. Torna-se então necessário que ocorra o estabelecimento de um elemento inicial de partilha entre os parceiros, sem a mediação do mundo externo (objetos), seguido da utilização de um "fundo” (o próprio sistema, ou seja, o elemento agora partilhado e o fluxo de ações dos parceiros) em relação ao qual as trocas são prolongadas e elaboradas pela inserção de outras ações (ou elementos). Finalmente, estas trocas podem adquirir um caráter abreviado, a partir da história de construção especifica da díade em estudo.

Partindo dessa exposição, entendemos que o modelo EEA, no que se refere a este tipo primeiro de troca dialógica, pode ser aplicado a diferentes culturas e a sujeitos dialógicos especiais (portadores de distúrbios sensoriais e/ou psicológicos).

As Trocas $M O B$. As trocas mediadas pelo mundo externo aos parceiros se caracterizam por incluírem uma parte deste mundo - conceituado como um "objeto" - como elemento dessas trocas. Classicamente, são essas trocas que têm sido estudadas como precursoras tanto da linguagem falada (Lock, 1980, 2001) como constitutivas do caráter de intencionalidade do parceiro, requisito fundamental para que se compreenda a diferenciação e constituição dos parceiros no diálogo (Tomasello, 1999).

A literatura na área atribui o advento desta intencionalidade em torno do que se constituiu chamar de "revolução dos nove meses" (Tomasello, 1999, dentre outros). Trevarthen (1998) chama esta fase, em que o bebê começa a discernir a intenção comunicativa do parceiro, de “ïntersubjetividade secundária”. O ponto relevante do modelo EEA está na capacidade de traçar a história de construção com o objeto anterior a esta fase do desenvolvimento da comunicação na qual se pode identificar claramente, como que já constituída, esta “intenção comunicativa”. Isto é feito utilizando o modelo EEA de maneira a focalizar a construção de um tipo particular de trocas mediadas pelo objeto, ou seja, aquelas que conduzem ao jogo de "dar-epegar o objeto" ou, dito de outra forma, ao "oferecimento do objeto, pela mãe, e a ação de pegá-lo, pelo bebê”.

Analogamente às trocas $\mathrm{FF}$, as trocas $\mathrm{MOB}$ também são passíveis de serem construídas mesmo que subsistam limitações de ordem sensorial ou psicológica nos parceiros. 
Mesmo limitações de ordem motora - claramente envolvidas na troca com o objeto - podem ser consideradas e investigadas. Este raciocínio é possível porque o essencial de uma troca MOB está na inclusão do mundo externo aos parceiros como elemento de troca. Assim, a substituição de modalidades ou habilidades sensoriais ou motoras é encarada pelo modelo EEA como possível e passível de investigação. Tal como foi dito em relação às trocas $\mathrm{FF}$, aqui, de forma análoga, o essencial é que se estabeleça uma atenção conjunta para o objeto, seguida do uso desta partilha como "fundo" (que é o próprio sistema em desenvolvimento) em relação a qual ações (elementos das trocas) são trabalhadas de forma prolongada e elaboradas pelos parceiros. Finalmente, é preciso investigar se estas trocas construídas pelos parceiros se abreviam.

\section{A Abreviação}

A partir de que tipo de análise as trocas abreviadas possibilitam a investigação do processo de emergência do self?

A té o atual estado de desenvolvimento do modelo EEA, um tipo de dado empírico nos fornece pistas deste processo de individuação. Trata-se da variabilidade interna a cada período de quase-estabilidade - estabelecimento, extensão e abreviação (para uma excelente leitura sobre este aspecto, ver o livro organizado por Granott, \& Parzialle, 2002, particularmente o capítulo escrito por van Geert).

Esta análise é realizada levando em conta que cada evento de troca entre os parceiros, classificado como estabelecimento, extensão ou abreviação, exibe uma variabilidade nas ações que compõem estas trocas diádicas. Utiliza-se o conceito de dinâmica dialógica de recorte como critério para distinguir as ações ou conjunto de ações que são "escolhidos ou recortados" pela díade para efetuar a troca entre os parceiros. Em seguida, essas variabilidades são agrupadas em subcategorias e são então identificadas na sua freqüência em cada registro (semanal em vídeo) das trocas mãebebê. Este procedimento é feito para as trocas FF e MOB.

A partir desta análise pode-se constatar tanto a variabilidade em termos da quantidade/número de subcategorias em cada um dos períodos de quase-estabilidade como, analisando cada uma dessas subcategorias, verificar a natureza dos seus componentes em relação à história da díade em estudo.

$\mathrm{O}$ aumento no número de subcategorias, tanto interno a cada período como ao longo do tempo considerando o mesmo período de quase-estabilidade em escrutínio, indica a flexibilidade do sistema para inovar. A diminuição indica o oposto. A natureza dos componentes das trocas em relação à história da díade em estudo permite inferir que tipo de variabilidade ocorre em cada um dos períodos de quaseestabilidade.

Estes dois tipos de análise nos possibilitaram reconhecer que é na abreviação que as trocas dialógicas entre os parceiros exibem um conhecimento partilhado que (a) apresenta uma "explosão para o novo" (Lyra \& Souza, 2003; Souza \& Lyra, 2000), (b) que é de natureza probabilística, e (c) que exibe uma característica de "índice duplo" (Surgan $\&$ De Lima, 2003). O primeiro aspecto refere-se ao aumento de subcategorias que se evidencia no período da abreviação. Por exemplo, tomando o exemplo de duas díades investigadas por Souza e Lyra; em uma delas encontramos 1 subcategoria durante o estabelecimento, 6 durante a extensão e 11 no período de abreviação; na outra díade esta "explosão" de subcategorias é ainda mais marcante, apresentado 1 subcategoria no período do estabelecimento, 6 naquele da extensão e 22 subcategorias durante a abreviação.

A natureza probabilística da abreviação pode ser analisada em relação à composição das ações, ou elementos, que constituem as trocas abreviadas considerando a história da díade. Este aspecto sugere que existe uma probabilidade desses elementos se comporem em cada troca, ao contrário de uma repetição ou uso de todos, sempre os mesmos, elementos (ações) que foram construídos como partilhados na história da díade. Assim, cada parceiro responde ao outro tendo o conhecimento de uma "totalidade" construída, pois não parece responder separadamente a elementos específicos que compõem esta "totalidade" abreviada. Por exemplo, considerando a abreviação das trocas FF, ao olhar acompanhado de um sorriso, o parceiro pode responder tanto somente com o olhar ou com o olhar mais vocalizações/fala.

$\mathrm{O}$ terceiro aspecto, que exibe a característica de “índice duplo", se infere também a partir da natureza dos componentes das trocas em relação à história da díade. Diante da progressiva "explosão" de novas subcategorias que ocorrem na abreviação, elementos completamente novos começam a serem introduzidos nessas trocas (isso ocorre mais da parte da mãe do que da parte do bebê, muito embora esta característica esteja presente no bebê também). Mesmo assim, a troca abreviada continua a ocorrer. Por quê? A nossa interpretação é que os parceiros começam a responder não apenas à mensagem contida no gesto ou ação per se, mas também à intenção do parceiro contida neste gesto. Por exemplo, nas trocas MOB, caracterizadas pelo "oferecimento do objeto, pela mãe, e a ação de pegá-lo, pelo bebê", a novidade é integrada - e respondida de forma abreviada porque a oferta do objeto (intenção da mãe) está incluída na qualidade abreviada da troca partilhada. Desta forma, do ponto de vista semiótico existe uma compreensão dupla da mensagem contida no oferecimento do objeto e na aceitação do objeto: uma primeira compreensão é diretamente inferida pelo parceiro a partir, digamos, da seqüência de ações já conhecida que conduzem à troca de dar-e-pegar; uma segunda compreensão diz respeito à mensagem contida no ofertar e no aceitar, que possibilita inovar. É importante ressaltar que, embora a inovação seja mais freqüente na mãe e a aceitação desta inovação seja mais freqüente no bebê, o fenômeno da compreensão da intenção está na díade ou é partilhado pela díade. Tanto o bebê inova e a mãe aceita, como a mãe "entende que o bebê entende", o que possibilita a ela inovar, mantendo a troca abreviada. É isto que chamamos de "índice duplo" (Surgan \& De Lima, 2003).

$\mathrm{O}$ que nos sugere o conjunto desses três aspectos? A natureza das trocas abreviadas possibilita discernir o surgimento de uma "realidade virtual" que é partilhada pelos parceiros. Nesta realidade cada parceiro existe e responde 
ao outro a partir da sua posição única construída, progressivamente, pela própria díade. A natureza probabilística e a característica de "índice duplo” da abreviação permitem aos parceiros transitar nesta "realidade virtual" demonstrando a sua posição única através da "escolha” de respostas que evidenciam "o lado de cada um dos parceiros” na história de construção de cada díade. Assim, adotando uma forma simplificada e utilizando o exemplo do "oferecimento do objeto, pela mãe, e a ação de pegá-lo, pelo bebê”, o bebê inova nas formas de pegar e a mãe naquelas de oferecer, mantendo a abreviação das trocas. Isto ocorre porque tudo o que o bebê e a mãe fazem frente ao outro (incluindo não fazer "nada") é resposta dialógica ao parceiro que mantém e projeta a abreviação para o futuro. O processo de emergência do self começa então a se evidenciar.

\section{A Unidade de Análise}

O modelo EEA propõe que são as trocas entre os parceiros ao longo do tempo que constituem a unidade de análise. A investigação é necessariamente longitudinal, e a análise é histórico-comparativa.

Quando se fala em unidade de análise na Psicologia, pelo menos intuitivamente, passamos a requerer uma fotografia (um ponto mais ou menos estático) e não um processo de mudança que deve ser possível de inferir a partir da própria unidade de análise. É bem verdade que só discernimos a transformação ou mudança a partir da comparação entre pontos mais ou menos estáticos. Trata-se de antigo dilema que remonta classicamente ao filósofo grego Heráclito. Todavia, pensamos que aqui se reflete a nossa dificuldade em ter a relação como objeto de estudo, particularmente a relação ao longo do tempo (Marková, 1987). Assim, a unidade de análise com a qual trabalhamos não é, por exemplo, e de forma simplificada, “o contato de olhar entre os parceiros" nas trocas FF, mas a comparação entre "o contato de olhar entre os parceiros", no momento 1 e "o contato de olhar entre os parceiros acompanhado de vocalizações, sorrisos, etc, por parte do bebê e/ou da mãe", no momento 2 . Também, não podemos dizer que a nossa unidade de análise se constitui nas trocas FF ou MOB, porque estes dois tipos característicos de comunicação são justamente o que queremos explicar nos seus processos de construção (isto é, a construção de um determinado, FF ou MOB, tipo de diálogo).

\section{O Modelo EEA: Possíveis Aplicações}

Podemos discernir três grupos de aplicações possíveis na utilização deste modelo. Um primeiro diz respeito à sua utilização no sentido de ampliar conhecimentos empíricos - mas, também, teóricos e metodológicos - acerca da área em estudo, ou seja, o estudo do processo de transformação e construção da comunicação mãe-bebê durante os primeiros meses de vida pós-natal do bebê. Por exemplo, variar as características dos parceiros da díade, elaborar teste experimental que manipule aspectos do sistema de comunicação no qual ocorre o estabelecimento, a extensão e a abreviação das trocas mãe-bebê.
Um segundo grupo refere-se à utilização deste modelo como fonte de identificação de desvios no desenrolar do processo de comunicação. É importante ressaltar que a identificação de possíveis desvios deve ser acompanhada da investigação da "recuperação desses desvios". Isto quer dizer que paralela à identificação de desvios está sempre a possibilidade da díade em foco encontrar caminhos alternativos ainda não investigados nem imaginados. Muito relacionado a este grupo está a possibilidade de o modelo EEA ser útil na orientação materna e na terapêutica.

Por fim, um terceiro grupo de aplicações se refere à possibilidade de utilizar este modelo para investigar outros tipos de parceiros e de processo de comunicação. Por exemplo, o processo de comunicação que ocorre entre professor-aluno, terapeuta-paciente, pai-bebê, criança-criança, etc. É importante ressaltar que neste caso são necessárias adaptações que, no entanto, devem preservar as características conceituais do modelo EEA, expressas no decorrer do presente trabalho e elaboradas por Lyra (particularmente em Lyra, 2007, no prelo).

\section{Referências}

Adamson, L. B. (1995). Communication development during infancy. Madinson, WI: Brown \& Benchmark.

Bakhtin, M. (1986). Speech genres and other late essays (C. Emerson \& M. Holquist, Eds.; V. W. McGee, Trad.). Austin, TX: University of Texas Press.

Bakhtin, M. (1993). Toward a Philosophy of the act (M. Holquist \& V. Liapunov, Eds.; V. Liapunov, Trad.) Austin, TX: University of Texas Press.

Bornstein, M. H., \& Tamis-LeMonda, C. S. (2001). Mother-infant interactions. In G. Bremner \& A. Fogel (Eds.), Infant development (pp. 269-295). Oxford, UK: Blackwell.

Bråten, S. (1988). Dialogic mind: The infant and the adult in proconversation. In M. Carvalho (Ed.), Nature, cognition and system (pp. 187-205). Dprdrecht, Holanda: Academic Press.

De Lemos, C. T. G. (1981). Interactional processes in child's acquisition of language. In W. Deutsch (Ed.), The child's construction of language (pp. 57-76). London: Academic Press.

De Lemos, C. T. G. (1985). Specularity as a constitutive process in dialogue and language acquisition. In L. Camaioni \& C. De Lemos (Eds.), Questions on social explanation (pp. 23-31). Amsterdam: John Benjamins.

Fogel, A. (1993). Developing through relationships. Origins of communication, self and culture._Chicago: University of Chicago Press.

Fogel, A., \& Lyra, M. C. D. P. (1997). Dynamics of development in relationships. In F. Masterpasqua \& P. Perna (Eds.), The Psychological meaning of chaos: Translating theory into practice (pp. 75-94). Washington, DC: American Psychological Association.

Fogel, A., Lyra, M. C. D. P., \& Valsiner, J. (1997). Introduction: Perspectives on indeterminism and development. In A. Fogel, M. C. D. P. Lyra \& J. Valsiner (Eds), Dynamics and indeterminism in developmental and social processes (pp. 1-10). Mahwah: NJ: Lawrence Erlbaum.

Granott, N., \& Parziale, J. (2002). Microdevelopment: A processoriented perspective for studying development and learning. In N. Granott \& J. Parziale (Eds.), Microdevelopment. Transition 
processes in development and learning(pp. 1-28). Cambridge, UK: Cambridge University Press.

Haken, H. (1983). Svnergetics: An introduction: Non-equilibrium phase transitions and self organization in Physics, Chemestry and Biology (3th. ed.). Berlin, Germany: Springer.

Hermans, H. J. M., \& Kempen, H. J. G. (1993). The dialogical self. Meaning as movement. New York: Academic Press.

Holquist, M. (1990). Dialogism. Bakhtin and his world. London: Routledge.

Império-Hamburger, A., Carvalho, A. M. A., \& Pedrosa, M. I. (2003). Movimentos ao acaso e princípios de ordenação em grupos de crianças brincando. In Tendências da Física Estatística no Brasil. Em homenagem ao Professor S. R. Salinas (pp. 105109). São Paulo, SP: Livraria da Física.

Lewis, M. D. (2000). The promising of dynamic systems approaches for an integrative account of human development. Child Development, 71(1), 36-43.

Lock, A. (1980). The guided reinvention of language. London: Academic Press.

Lock, A. (2001). Preverbal communication. In G. Bremner \& A. Fogel (Eds.), Infant development (pp. 404-426). Oxford, UK: Brackwell.

Lyra, M. C. D. P. (1998). Reflections on the dynamics of meaning making: Communication process at the beginning of life. In M. C. D. P. Lyra \& J. Valsiner (Eds.), Construction of psychological processes in interpersonal communication: Vol. 4. Advances in child development within culturally structured environments (pp. 225242). Norwood, NJ: Ablex.

Lyra, M. C. D. P. (2000). Desenvolvimento como processo de mudança em um sistema de relações historicamente construído: Contribuições do estudo da comunicação no início da vida. Psicologia: Reflexão e Crítica, 13(2), 257-268.

Lyra, M. C. D. P. (2006). O modelo EEA para a investigação da emergência e desenvolvimento da comunicação e do self. Bases conceituais e fundamentos teórico metodológicos. Estudos de Psicologia 2006, 11 (1), 25-33.

Lyra, M. C. D. P. (no prelo). Mother-infant communication development and the emergence of self: The contributions of dynamic systems and dialogism. In C. Lightfoot, M. C. D. P. Lyra (Eds.), Challenges and strategies for studying human development in cultural contexts. Roma: Carlo Amore Edizioni.

Lyra, M. C. D. P., \& Rossetti-Ferreira, M. C. (1995). Transformation and construction in social interaction: A new perspective on analysis of the mother-infant dyad. In J. Valsiner (Ed.), Child development within culturally structured environment: Vol 3. Comparative cultural-constructivist perspective (pp. 51-77). Norwood, NJ: Ablex.

Lyra, M. C. D. P., \& Souza, M. (2003). Dynamics of dialogue and emergence of self in early communication. In I. Josephs (Ed.), Dialogicality in development: Vol. 5. Advances in child development culturally structured environments (pp. 51-68). Greenwhich, CT: Ablex.

Lyra, M. C. D. P., \& Winegar, L. T. (1997). Processual dynamics of interactions through time: Adult-child interactions and process of development. In A. Fogel, M. C. D. P. Lyra \& J. Valsiner (Eds.), Dynamics and indeterminism in developmental and social processes (pp. 93-109). Mahwah, NJ: Lawrence Erlbaum.

Marková, I. (1987). On the interaction of opposites in psychological processes. Journal for the Theory of Social Behaviour, 17, 279-299.
Marková, I. (1990). A three-step process as a unit of analysis in dialogue. In I. Marková \& K. Foppa (Eds.), The dynamics of dialogue (pp. 129-146), New York: Springer-Verlag.

Molenaar, P. C. M., \& Valsiner, L. (2005). How generalization works through the single case: A simple idiographic process analysis of an individual psychotherapy. International Journal of Idiographic Science, 1. Retrieved from http:// www.valsiner.com

Nesselroade, J. R., \& Molenaar, P. C. M. (2003). Quantitative models for developmental processes. In J. Valsiner \& K. Connolly (Eds.), Handbook of Developmental Psychology (pp. 622639). London: Sage.

Pantoja, A. P. F., \& Nelson-Goens, G. C. (2000). Desenvolvimento da vida emocional durante o segundo ano de vida: Narrativas e sistemas dinâmicos. Psicologia: Reflexão e Crítica, 13(2), 269-280.

Schaffer, H. R. (1984). The child's entry into a social world. New York: Academic Press.

Sinhá, C. (2004, November). Practice, process and sign in meaning construction. Paper presented at the Third Serrambi Meetings: Methods for Studying Human Development in Culturally Diverse Contexts, Serrambi, PE.

Souza, M., \& Lyra, M. C. D. P. (2000). Develoment of early communication: Contributions from a dynamic, historical, and dialogical approach. In III Conferência de Pesquisa Sócio Cultural, Campinas, SP, 2000. Retrieved from http:// www.fae.unicamp.br/br2000.

Surgan, S., \& De Lima, S. (2003). Integrating indexicals in simian semiotics: Symbolic development and culture. The Journal of Mind and Behavior, 24(3), 317-338.

Thelen, E., \& Smith, L. B. (1994). A dynamic system approach to the development of cognition and action. Cambridge, MA: MIT Press.

Thelen, E., \& Ulrich, B. D. (1991). Hidden skills: A dynamic systems analysis of treadmill stepping during the first year. Monographs of the Society for Research in Child Development, 56(1).

Tomasello, M. (1999). The cultural origins of human cognition. Cambridge, MA: Harvard University Press.

Trevarthen, C. (1998). The concept and foundations of infant intersubjectivity. In S. Bråten (Ed.), Intersubjective communication and emotion in early ontogeny (pp. 15-46). Cambridge, UK: Cambridge University Press.

Valsiner, J. (2001). Comparative study of human cultural development. Madri, España: Fundacion Infancia y Aprendizage.

Valsiner, J. (2002). Irreversibility of time and ontopotentiality of signs. Estudios de Psicologia, 23(1), 49-59.

van Geert, P. (1994). Dynamic sistems of development: Change between complexitv and chaos. New York: Harvester.

van Geert, P. (2002). Developmental dynamics, intention actions and fuzzy sets. In N. Granott \& J. Parziale (Eds.), Microdevelopment. Transition processes in development and learning sets (pp. 319-343). Cambridge, UK: Cambridge University Press.

Vygotsky, L. S. (1986). Thought and language(Rev. ed.). Cambridge, MA: MIT Press. 